\title{
Tıkayıcı Uyku Apne Sendromu Hastalarında Farklı Yaş Grupları Arasındaki Vücut Kitle İndeksi ve Apne Hipopne İndeksi Arasındaki İlişkinin Karşılaştırılması
}

\author{
Süleyman Emre KARAKURT, Nurcan KUM, Mehmet Ali ÇETİN, \\ Serdar ENSARİ, Mehmet Fatih KARAKUŞ, Hüseyin DERE
}

Ankara Numune Eğitim ve Araştırma Hastanesi, Kulak Burun Boğaz ve Baş Boyun Cerrahisi Kliniği, Ankara.

\begin{abstract}
ÖZET
Obezite tıkayıcı uyku apne sendromu (TUAS) için iyi tanımlanmış bir risk faktörüdür, ancak obezitenin TUAS gelişim riski üzerine etkileri, farklı yaş gruplarında farklı bulunmuştur. Bu çalışma ile farklı yaş gruplarında, vücut kitle indeksi (VKİ) ile apne hipopne indeksi (AHI) arasındaki ilişkinin araştırılması ve obezitenin TUAS ağırlı̆̆ üzerine etkilerinin yaş grupları arasındaki farkının araştırılması amaçlandı. TUAS ön tanısı ile tüm gece polisomnografisi yapılan hastaların polisomnografik kayıtları retrospektif olarak incelendi. Çalışmaya dahil edilme kriterlerini karşılayan 236 hasta, yaş aralıklarına göre 4 farklı gruba ayrıldı. Grupları sırası ile 40 yaş altı, 41-50 yaş arası, 51-60 yaş arası ve 60 yaş üstü hastalar oluşturdu. Tüm hastaların ve her bir grubun VKİ ve AHİ'leri arasındaki korelasyon araştırıldı. Altmış yaş üstü hasta grubu haricindeki tüm gruplarda VKİ ile AHİ arasında istatistiki anlamlı aynı yönlü korelasyon saptandı. Literatürle uyumlu olarak ileri yaş grubunda obezitenin TUAS şiddeti üzerine etkisi, diğer yaş gruplarına göre daha düşük olduğu sonucuna ulaşıldı.
\end{abstract}

Anahtar Kelimeler: Tıkayıcı uyku apnesi. Beden kitle indeksi. Yaş.

Comparison of the Relationship Between Body Mass Index and Apnea Hypnoea Index in Different

Age Groups in Obstructive Sleep Apnea Syndrome Patients

\begin{abstract}
Obesity is a well-defined risk factor for obstructive sleep apnea syndrome (OSAS), but the effects of obesity on OSAS development risk are different in different age groups. The aim of this study was to investigate the relationship between body mass index (BMI) and apnea hypopnea index (AHI) in different age groups and to investigate the effect of obesity on OSAS severity among age groups. Polysomnographic records of patients who underwent whole night polysomnography with OSAS pre-diagnosis were retrospectively reviewed. Two hundred thirty-six patients who met the inclusion criteria were divided into 4 groups according to their age range. The groups were composed of patients under the age of 40, between the ages of 41-50, between the ages of 51-60 and over 60. Correlations between BMI and AHI of all patients and each group were investigated. There was a statistically significant correlation between BMI and AHI in all groups except patients over 60 years of age. .In accordance with the literature, the effect of obesity on OSAS severity in the elderly group was found to be lower than in the other age groups.
\end{abstract}

Key Words: Obstructive sleep apnea. Body mass index. Age.

Geliş Tarihi: 04 Mayıs 2018

Kabul Tarihi: 27 Kasım 2018

* 13. Uluslararası Kulak Burun Boğaz ve Baş Boyun Cerrahisi Kongresi'nde (5-7 Nisan 2018, Ankara) sözlü bildiri olarak sunulmuştur.

Dr. Süleyman Emre KARAKURT

Ankara Numune Eğitim ve Araştırma Hastanesi, Kulak Burun Boğaz ve Baş Boyun Cerrahisi Kliniği,

Ankara.

Tel.: 05338102743

E-posta: suleymanemrekarakurt@gmail.com
T1kayıcı uyku apne sendromu (TUAS) en sık karşılaşılan uykuda solunum bozukluğudur ve kadınların \%3-7'sini, erkeklerin \%2-5'ini etkiler ${ }^{1,2}$. Orta yaşta prevalansı \%2-4 arasında iken, ileri yaşlarda bu oran \%20'nin üzerine çıkar ${ }^{3-5}$. Yaşla birlikte TUAS prevalansı artmakla birlikte, obezite TUAS gelişiminde yaşlanmadan daha büyük bir etkiye sahiptir ${ }^{1}$. Obezite TUAS için iyi tanımlanmış bir risk faktörüdür, ancak, yapılan az sayıda çalışma ile, obezitenin TUAS riski üzerine etkileri, farklı yaş gruplarında, farklı bulunmuştur ${ }^{1,6}$. Bu çalışmanın amacı farklı yaş gruplarında, vücut kitle indeksi (VKİ) ile apne hipopne indeksi (AHI) arasındaki ilişkiyi araştırmak ve obezitenin TUAS ağırlığı üzerine etkilerinin gruplar arasındaki farkını araştırmaktır. 


\section{Gereç ve Yöntem}

Araştırma için Etik Kurul izni alınmıştır (Karar no: E17-1711). Kliniğimize Ocak 2016-Ocak 2018 tarihleri arasında, horlama, aşırı gündüz uykuluk hali ve tanıklı apne şikayetleri ile başvuran ve TUAS ön tanısı ile tüm gece polisomnografisi yapılan hastaların polisomnografik kayıtları retrospektif olarak incelendi. Uyku etkinliği \%60'ın altında olan hastalar ile AHİ'si 5 'in altında olan hastalar çalışmadan dışlandı. Çalışmaya dahil edilme kriterlerini karşılayan 236 hasta, yaş aralıklarına göre dört farklı gruba ayrıldı. Grupları sırası ile 40 yaş altı, 41-50 yaş arası, 51-60 yaş arası ve 60 yaş üstü hastalar oluşturdu. Tüm hastaların ve her bir grubun VKİ ve AHI'leri arasındaki korelasyon araştırıld1.

\section{Ístatistiki Analiz}

Verilerin dağılımını değerlendirmek için KolmogorovSmirnov testi kullanıldı. Ortalamalar standart sapma ile birlikte verildi. Yaş grupları arasındaki cinsiyet dağılımı farkı Ki-kare testi ile değerlendirildi. VKİ ve AHİ arasındaki ilişki Spearman's rho korelasyon testi ile değerlendirildi. $\mathrm{P}<0.05$ değeri anlamlı olarak kabul edildi. İstatistiksel değerlendirme için SPSS statistical software (SPSS forWindows, version 21.0; SPSS Inc., Chicago, IL, USA) kullanıldı.

\section{Bulgular}

Hastaların 79'u kadın,157'si erkek hastalardan oluşuyordu. Hastaların ortalama yaşı $49.3 \pm 10.43$ olarak saptandı. Hastalar yaş gruplarına göre sınıflandırıldıklarında 40 yaş altı grubu 45 hasta, 41-50 yaş arası grubu 80 hasta, 51-60 yaş arası grubu 79 hasta ve 60 yaş üstü grubu 32 hasta oluşturdu. Hastaların gruplara göre demografik özellikleri tablo I’de gösterilmiştir.

Tablo I. Hasta gruplarının demografik özellikleri

\begin{tabular}{|l|c|c|c|c|c|}
\hline & $\begin{array}{c}40 \text { yaş altı } \\
(n=45)\end{array}$ & $\begin{array}{c}41-50 \text { yaş } \\
(n=80)\end{array}$ & $\begin{array}{c}51-60 \text { yaş } \\
(n=79)\end{array}$ & $\begin{array}{c}60 \text { yaş üstü } \\
(n=32)\end{array}$ & $p$ \\
\hline Kadın & 9 & 21 & 36 & 13 & 0.09 \\
\hline Erkek & 36 & 59 & 43 & 19 & \\
\hline
\end{tabular}

Tüm hastalar değerlendirildiğinde VKİ ve AHİ arasında pozitif yönlü istatistiki olarak anlamlı korelasyon saptand $1(\mathrm{p}<0.001, \mathrm{r}=0.284)$. Yaş gruplarına göre VKİ ve AHİ korelasyonları değerlendirildiğinde 40 yaş altı grup, 41-50 yaş arası grup ve 51-60 yaş arası grupta pozitif yönlü istatistiki olarak anlamlı korelasyon saptand 1 ( $\mathrm{p}=0.014, \mathrm{r}=0.365 ; \mathrm{p}=0.019, \mathrm{r}=0.261$; $\mathrm{p}=0.001, \mathrm{r}=0.355) .60$ yaş üstü grupta VKİ ve AHİ arasında anlamlı korelasyon saptanmadı $(\mathrm{p}=0.477)$ (Tablo II).
Tablo II. Tüm hastalar ve yaş gruplarındaki VKİ ve AHİ korelasyonu

\begin{tabular}{|c|c|c|}
\hline & $\mathbf{p}$ & $\mathbf{r}$ \\
\hline Tüm Hastalar & 0.001 & 0.284 \\
\hline 40 yaş altı & 0.014 & 0.365 \\
\hline 41-50 yaş arası & 0.019 & 0.261 \\
\hline $\mathbf{5 1 - 6 0}$ yaş arası & 0.001 & 0.355 \\
\hline $\mathbf{6 0}$ yaş üstü & 0.477 & \\
\hline
\end{tabular}

\section{Tartışma}

TUAS uyku esnasında tekrarlayan faringeal kollapslar ile karakterizedir ve oksijen desatürasyonuna, bölünmüş uykuya, gündüz uykululuğuna ve kardiyovasküler komplikasyonlara neden olur ${ }^{1}$. Obezite TUAS gelişiminde risk faktörüdür ve normal aralığın \%10'undan fazla kilo artışı, bu hastalığın gelişimi için artmış risk oluşturur $^{7}$. Obezitenin TUAS gelişimi riskini arttırmas1 lateral havayolu duvarındaki yağ dokusunun neden olduğu azalmış faringeal lümen çapı, kas içinde biriken yağ dokusunun neden olduğu azalmış üst havayolu kas gücü ve genişlemiş karnın gögüs duvarı üzerindeki kitle etkisinin neden olduğu azalmış üst havayolu çap1 ile açıklanabilir ${ }^{8-10}$. Obezitenin TUAS gelişimi üzerine etkisi birçok araştırmanın konusu olmuştur. Yapılan bir çalışmada vücut ağırlığındaki \%1'lik azalmanın, AHI'de \%3'lük azalmaya neden olduğu saptanmıştır ${ }^{4}$. Benzer şekilde bariatrik cerrahi geçiren 25 hastanın incelendiği bir çalışmada ameliyat öncesi ve ameliyat sonrası kilo kaybı ve AHİ değerleri karşılaştırılmış ve ortalama 45 kiloluk kaybın AHI'de 62 'den 13 'e düşüşe yol açtığı saptanmıştır ${ }^{11}$. Çalışmamızda literatürle uyumlu şekilde VKİ ve AHİ arasında aynı yönlü ilişki saptandı.

Obezite TUAS için iyi bilinen bir risk faktörü olmas1na rağmen, obezite ve TUAS arasındaki ilişki yaş gruplarına göre farklılık gösterir ${ }^{12}$. Yaşlı hastalarda obezitenin TUAS gelişimi üzerine etkisinin diğer yaş gruplarına göre daha düşük olduğunu gösteren çalışmalar mevcuttur ${ }^{1,6}$. Özellikle 70 yaş üzerinde TUAS ve obezite arasında ilişkinin zayıf olduğu belirtilmektedir $^{13}$. Lee ve arkadaşları yaptıkları çalışma ile obezite ile AHİ arasındaki ilişkinin yaş gruplarına göre farklılık gösterdiğini saptamışlardır. Orta yaşlarda VKİ ve AHİ arasında istatistiki anlamlı korelasyon mevcutken, 30 yaş altı ve 70 yaş üstü hasta grubunda anlamlı korelasyon bulamadıklarını belirtmişlerdir ${ }^{12}$. Çalışmamızda 40 yaş altı, 41-50 yaş arası ve 51-60 yaş arası hasta gruplarında VKİ ve AHİ arasında anlamı korelasyon bulunurken, 60 yaş üstü grupta VKI ve AHİ arasında anlamı korelasyon saptanmadı.

Obezite ile TUAS şiddeti arasındaki ilişkinin farklı yaş gruplarında değişkenlik göstermesinin sebebi tam olarak anlaşılamamıştır. Yaş ile birlikte havayolu yapısındaki değişiklikler bu farklılığın sebebini açık- 


\section{Vücut Kitle İndeksi ve Apne Hipopne İndeksi}

layabilir $^{12}$. Yaş ile birlikte üst havayolu direnci artmakta ve üst havayolu kas fonksiyonu azalmaktad $11^{14,15}$. Bu faktörlerin yaşlı hasta grubunda TUAS şiddeti üzerine obeziteden daha etkili olmaları mümkündür. Çalışmamızdan elde edilen bulgular, ileri yaş grubunda obezitenin TUAS şiddeti üzerinde etkili bir faktör olmadığını destekler nitelikte bulundu.

Çalışmaya dahil edilen hastaların sefalometrik incelemelerinin yapılmamış olması ve antropometrik ölçüm olarak sadece vücut kitle indeksinin kullanılması ve boyun çevresi, bel çevresi ve kalça çevresi gibi ek antropometrik ölçümlerin kullanılmamış olması çalışmamızın zayıf yönünü oluşturmaktadır. Çalışmanın bir diğer kısıtlılığı, sigara kullanımı, komorbid hastalık varlığı ve ilaç kullanımı gibi TUAS ağırlığını etkiliyebilecek faktörlerin yaş grupları arasında homojen olarak dağılmamasıdır.

Obezite TUAS gelişiminde önemli bir risk faktörüdür. Obezitenin TUAS şiddeti üzerine etkisi yaş gruplarına göre farklılık göstermektedir. Özellikle ileri yaş grubunda VKİ'nin AHİ üzerine, dolayısı ile obezitenine TUAS şiddeti üzerine etkisi, diğer yaş gruplarına göre daha düşüktür. $\mathrm{Bu}$ farklılığın sebebi, ileri yaşlarda artan üst havayolu direnci ve üst havayolu kas fonksiyonundaki azalmanın TUAS patojenezi üzerine obeziteden daha etkili faktörler olması ile açıklanabilir.

\section{Kaynaklar}

1. Degache F, Sforza E, Dauphinot V, et al. Relation of central fat mass to obstructive sleep apnea in the elderly. Sleep 2013;36:501-7.

2. Young T, Peppard PE, Taheri S. Excess weight and sleepdisordered breathing. J Appl Physiol (1985) 2005;99:15921599.
3. Young T, Palta M, Dempsey J, Skatrud J, Weber S, Badr S. The occurrence of sleep-disordered breathing among middle-age dadults. N Engl J Med 1993;328:1230-5.

4. Young T, Peppard PE, Gottlieb DJ. Epidemiology of obstructive sleep apnea: a population health perspective. Am J Respir Crit Care Med 2002;165:1217-39.

5. Ancoli-Israel S, Kripke DF, Klauber MR, Mason WJ, Fell R, KaplanO. Sleep-disordered breathing in community-dwelling elderly. Sleep 1991;14:486-95.

6. Carmelli D, Swan GE, Bliwise DL. Relationship of 30-year changes in obesity to sleep-disordered breathing in the Western Collaborative Group Study. ObesRes 2000;8:632-637.

7. Newman AB, Nieto FJ, Guidry U, et al. Relation of sleepdisorderedbreathingtocardiovasculardisease risk factors: theSleepHeartHealthStudy. Am J Epidemiol 2001;154:50-9.

8. Horner RL, Mohiaddin RH, Lowell DG, et al. Sites and sizes of fat deposits around the pharynx in obese patients with obstructive sleep apnea and weight matched controls. EurRespir J 1989;2:613-22.

9. Mohsenin V. Gender differences in the expression of sleepdisordered breathing: role of upper airway dimensions. Chest 2001;120:1442-7.

10. Mortimore IL, Marshall I, Wraith PK, Sellar RJ, Douglas NJ. Neck and total body fat deposition in nonobese and obese patients with sleep apnea compared with that in control subjects. Am J RespirCritCareMed 1998;157:280-3.

11. Dixon JB, Schachter LM, O'Brien PE. Polysomnography before and after weight loss in obese patients with severe sleep apnea. Int J Obes (Lond) 2005;29:1048-54.

12. Lee YG, Lee YJ, Jeong DU. Differential effects of obesity on obstructive sleep apnea syndrome according to age. PsychiatryInvestig 2017;14:656-661.

13. Newman AB, Foster G, Givelber R, Nieto FJ, Redline S, Young T. Progression and regression of sleep-disordered breathing with changes in weight: the Sleep Heart Health Study. ArchInternMed 2005;165:2408-2413.

14. Eikermann M, Jordan AS, Chamberlin NL, et al. The influence of aging on pharyngeal collapsibility during sleep. Chest 2007;131:1702-1709.

15. Veldi M, Vasar V, Hion T, Kull M, Vain A. Ageing, softpalatet one and sleep-related breathing disorders. ClinPhysiol 2001;21:358-364 
